\title{
The Risk-Return Relationship in Crude Oil Markets during COVID-19 Pandemic: Evidence from Time-Varying Coefficient GARCH-in-Mean Model
}

\author{
Napon HONGSAKULVASU ${ }^{1}$, Asama LIAMMUKDA ${ }^{2}$
}

Received: July 25, 2020 Revised: August 23, 2020 Accepted: August 28, 2020

\begin{abstract}
In this paper, we propose the new time-varying coefficient GARCH-in-Mean model. The benefit of our model is to allow the risk-return parameter in the mean equation to vary over time. At the end of 2019 to the beginning of 2020, the world witnessed two shocking events: COVID-19 pandemic and 2020 oil price war. So, we decide to use the daily data from December 2, 2019 to May 29, 2020, which cover these two major events. The purpose of this study is to find the dynamic movement between risk and return in four major oil markets: Brent, West Texas Intermediate, Dubai, and Singapore Exchange, during COVID-19 pandemic and 2020 oil price war. For the European oil market, our model found a significant and positive risk-return relationship in Brent during March 26-April 21, 2020. For the North America oil market, our model found a significant positive risk return relationship in West Texas Intermediate (WTI) during March 12-May 8, 2020. For the Middle East oil market, we found a significant and positive risk-return relationship in Dubai during March 12-April 14, 2020. Lastly, for the South East Asia oil market, we found a significant positive risk return relationship in Singapore Exchange (SGX) from March 9-May $29,2020$.
\end{abstract}

Keywords: Time-Varying Coefficient, Risk-Return Relationship, GARCH-in-Mean Model, Oil Price War, COVID-19

JEL Classification Code: C14, C22, C58, G15, Q49

\section{Introduction}

Crude oil is one of the very important commodities that drive the world economy since it is one of the main energy sources that we rely on these days. The price of crude oil is determined by the power of demand and supply in the market. Even though, the crude oil price in the future market fluctuated much, it induces many investors to take a risk for a great return. Then, to study the risk-return relationship in crude oil market is one of the interesting topics in financial and economics fields. Merton's intertemporal capital asset pricing model describes that the investor has always expected

${ }^{1}$ First Author and Corresponding Author. Lecturer, Faculty of Economics, Chiang Mai University, Thailand [Postal Address: 239 Huay Kaew Road, Tambon Su Thep, Mueang Chiang Mai District, Chiang Mai 50200, Thailand] Email: hongsakulvasu@gmail.com ${ }^{2}$ Ph.D. Student, Department of Statistics, Faculty of Science, Chiang Mai University, Thailand. Email: asama.liammukda@gmail.com.

(c) Copyright: The Author(s)

This is an Open Access article distributed under the terms of the Creative Commons Attribution Non-Commercial License (https://creativecommons.org/licenses/by-nc/4.0/) which permits unrestricted non-commercial use, distribution, and reproduction in any medium, provided the original work is properly cited. for more return in order to compensate the higher risk, then he proposed that the risk and return relationship should be positive (Merton, 1973).

From the end of 2019 to the beginning of 2020, we have two major crises, the COVID-19 pandemic and the 2020 oil price war, which affect directly the crude oil market. The new Corona Virus, called COVID-19, starts to spread from Wuhan, China, at the beginning of December 2019. The World Health Organization (WHO) announces COVID-19 as a pandemic on March 11, 2020. During the COVID-19 pandemic, almost every country decided to use the 'lockdown' strategy - closing the whole country in order to stop the spread of the virus. Since many economic activities have had to stop, especially land and air travels, the demand for crude oil had dropped heavily. U.S. Energy Information Administration (2020) predicted that the demand for liquid fuels will drop from 100 million barrels per day to 80 million barrels per day in the second quarter of 2020 .

Since the demand for oil had been declining, OPEC's leader, Saudi Arabia, wanted to sustain the price of crude oil by organizing a meeting between OPEC members and non-OPEC oil exporter countries, such as Russia, to lower the global oil production. However, the talk between Saudi 
Arabia and Russia failed on March 8, 2020. Then, both countries announced that they will produce more oil in the global market. In 2019, the oil production from Saudi Arabia and Russia accounted for $23 \%$ of the world market. The failure of the March 8, 2020 meeting led to the crude oil price falling heavily. So, it can be said that March 8, 2020, marks the beginning of the 2020 oil price war.

The price of crude oil in the beginning of 2020 has been fluctuating due to the timeline of COVID-19 pandemic and the oil price war. Then, the question is: "What will the risk-return relationship be during these crises?" One of the workhorses for the risk-return study is the GARCH-in-Mean model (Engle et al., 1987). GARCH-in-Mean model has been used heavily to study the risk-return relationship in stock markets around the world (Nguyen \& Nguyen, 2019; Sahadudheen, 2015). However, the risk-return relationship parameter that GARCH-in-Mean provides is a time-invariant parameter. So, it would be productive if we have a model that can provide the risk-return relationship parameter that is allowed to change over these crises. In the nutshell, our paper proposes the new time-varying coefficient GARCHin-Mean Model using GAM method to study the riskreturn relationship in four major crude oil markets during COVID-19 pandemic and 2020 oil price war.

This paper is organized as follows: section 2 describes the literature review; section 3 presents the model; section 4 describes the data; section 5 shows the results; the summary is presented in the last section.

\section{Literature Review}

To understand the risk-return relationship in crude oil market is one of the interesting topics for the researcher. However, the results of this topic are still inconsistent, and may depend on the time period, the length of the data sets, and the models used. Some papers report that the risk and return have a positive relationship, while other studies report a negative relationship.

Cifarelli and Paladino (2010) found a positive risk return relationship on WTI crude oil spot price from October 6, 1992, to June 24, 2008, by using GARCH-in-Mean model. Gong et al. (2017) reported a positive contemporaneous relationship between risk and return of WTI crude oil between January 1998 and April 2014. However, they found a negative and insignificant intertemporal risk-return relationship. Cotter and Hanly (2010) applied the GARCH-in-Mean model to study the risk-return relationship of Unleaded Gasoline in NYMEX from February 19, 1992, to October 29, 2008, and found that the relationship between risk and return is positive. Abduikareem and Abdulhakeem (2016) also used the GARCH-in-Mean model and found a positive relationship of risk and return in Nigerian crude oil market between January 1987 and June 2017. In addition, Deebom and Essi (2017) found a negative effect of asymmetric term in volatility equation on Nigerian crude oil market.

On the other hand, Li et al. (2013) reported a negative intertemporal relationship between risk and return by using GARCH-in-Mean model on the oil future price data from U.S. Energy Information Administration (EIA) from April 4, 1983, to February 28, 2012. Trolle and Schwartz (2008) also found a negative relationship between risk and return of NYMAX crude oil between January 2, 1996, and November 30, 2006. Moreover, Kristoufek (2014) reported a negative relationship between return and volatility risk of Brent and WTI crude oil.

In summary, the inconsistence of the studies may come from the special events, such as economics crisis and war that happen during the period of the dataset in their studies. Unfortunately, GARCH-in-Mean model can provide only time-invariant parameters, which cannot be varied to account for special events. So, it is the main purpose of this paper to present the new time-varying coefficient GARCH-in-Mean model that can provide the risk-return parameter that can be changed over time. Moreover, we apply our new model to study the risk-return relationship in four major oil markets from December 2019 to May 2020 marked by two special events, COVID-19 pandemic and 2020 oil price war, that heavily affected oil markets around the world.

\section{Research Methods}

\subsection{Model}

One of the popular models that can capture the relationship between risk and return is GARCH-in-Mean model proposed by Engle et al. (1987). The model allows for the conditional variance to be varied over time, which is called the heteroskedasticity condition, and the model treats the conditional variance as the risk of the asset we want to study. Equation (3) shows the variance equation in the form of Bollerslev (1986)'s GARCH $(1,1)$ in which the conditional variance or risk $(h)$ depends on one lagged period of squared shock $\left(\varepsilon_{t-1}^{2}\right)$ and one lagged period of risk $\left(h_{t-1}\right)$ itself. Equation (1) shows the mean equation which capture the contemporaneous relationship between return $\left(r_{t}\right)$ and risk $\left(h_{t}\right)$.

$$
\begin{gathered}
r_{t}=c+\gamma h_{t}+\varepsilon_{t} \\
\varepsilon_{t}=\xi_{t} \sqrt{h_{t}} \\
h_{t}=\omega+\alpha \varepsilon_{t-1}^{2}+\beta h_{t-1}
\end{gathered}
$$

where $r_{t}$ is the returns, $\mathbb{E}\left(\varepsilon_{t} \mid \mathcal{F}_{t-1}\right)=0,\left(\varepsilon_{t}^{2} \mid \mathcal{F}_{t-1}\right)=h_{t}, h_{t}$ is the conditional variance or risk and $\xi_{t} \sim i . i . d .(0,1)$

The drawback of traditional GARCH-in-Mean model is that the parameters $(c, \gamma)$ in the mean equation which 
captures the risk return relationship are time-invariant. So, it means that over the period of the data that we put in the model, the relationship between risk and return will be fixed. The challenge arrives when we have special situations, such as the 2020 oil price war between Saudi Arabia and Russia and COVID-19 pandemic, which the risk-return relationship may change over time.

Our paper proposes the new time-varying coefficient GARCH-in-Mean model by allowing the parameters $(c, \gamma)$ in the mean equation to be varied over time, while the variance equation is still in the form of $\operatorname{GARCH}(1,1)$. So, equation (1) will be changed to the following equation.

$$
r_{t}=c_{t}+\gamma_{t} h_{t}+\varepsilon_{t}
$$

Since, the return $\left(r_{t}\right)$ series come directly from the data set, if we can estimate the risk $\left(h_{t}\right)$, then we can easily estimate the time varying parameters $\left(c_{t} \gamma_{t}\right)$ by using the Generalized Additive Model (GAM) from Hastie and Tibshirani (1990) and Wood (2006). GAM uses the technique of non-parametric smooth function, which is based on regression splines. To understand how to estimate the time-varying coefficient, we simplified the model to have only one time-varying coefficient to be estimate as it is shown in the following equation (Bringmann et al., 2017).

$$
r_{t}=c_{t}+\varepsilon_{t}
$$

The time-varying coefficient $\left(c_{t}\right)$ can be estimated by using regression splines method as the following equation.

$$
\hat{c}_{t}=\widehat{\alpha}_{1} R_{1}(t)+\widehat{\alpha}_{2} R_{2}(t)+\hat{\alpha}_{3} R_{3}(t)+\ldots+\widehat{\alpha}_{K} R_{K}(t)
$$

After choosing the type of basis function $R()$ and the number of basis function $(K)$, we can estimate $\hat{c}_{t}$ by using a simple linear regression. For the easiest example, a polynomial with order 4 can be used as the basis function, then we have $R_{1}(t)=1, R_{2}(t)=t, R_{3}(t)=t^{2}, R_{4}(t)=t^{3}, R_{5}(t)=t^{4}$, (Wood, 2006). We can call this method as a data driven approach, since each basis function can be calculated from the data. The coefficient $\left(\hat{\varepsilon}_{\mathrm{r}}\right)$ that we estimate from equation (6) can be either linear or non-linear shape which is depended on time. In our paper, we use a thin-plate regression splines as the basis function in the model since it is the default setting in the R program package names "mgcv". Thin-plate regression splines offer some advantage since it doesn't need to provide the knot locations and it performs very well when we put more independent variables into the model (Wood, 2003).

$$
\sum_{t=1}^{T}\left[y_{t}-c_{t}\right]^{2}+\lambda \int_{-\infty}^{+\infty}\left[c_{t}^{\prime \prime}\right]^{2} d t
$$

The equation (7) can be minimized in order to get the optimal value of time-varying coefficient $\left(\hat{c}_{t}\right)$. Equation (7) has a smoothing parameter $\lambda$ which will balance between the linear least square term on the left and the wiggliness penalty term on the right. The value of a smoothing parameter $\lambda$ will affect the shape of time-varying coefficient $\left(\hat{c}_{t}\right)$. In the case that the value of $\lambda$ is high, the wiggliness penalty will be large, then the time-varying coefficient $\left(\hat{c}_{t}\right)$ will be a linear line. On the other hand, if the value of $\lambda$ is low, the wiggliness penalty will be small, then the time-varying coefficient $\left(\hat{c}_{t}\right)$ will be a non-linear line. Then, it comes to the next question, how to get the optimal value of a smoothing parameter $\lambda$.

$$
G C V=\frac{T \sum_{t=1}^{T}\left(y_{t}-\hat{\beta}_{0, t}\right)^{2}}{[\operatorname{tr}(I-A)]^{2}}
$$

From Wahba (1980) and Wood (2006), the value of $\lambda$ which provides the minimum number of the generalized Cross Validation (GCV) score in equation (8), will be the optimal value. By performing equation (6), (7) and (8) together, we will get the optimal value of the time-varying coefficient.

The simple model in equation (5) can be easily extended to include more independent variables and time-varying coefficients (Wood, 2006). Time-varying model using GAM approach becomes more popular in the field of time-series econometrics. Bringmann et al. (2017) applied time-varying coefficient model using GAM approach to the autoregressive model to study in psychology area while Hongsakulvasu and Liammukda (2020) used timevarying coefficient autoregressive model to study Asian stock markets. In additional, Haslbeck et al. (2017) applied time-varying coefficient model using GAM approach to the Vector Autoregressive model. However, our paper is the first to apply time-varying coefficient model using GAM approach to the GARCH-in-Mean model. Then, our timevarying coefficients GARCH-in- Mean model is shown in the following equations.

$$
\begin{gathered}
r_{t}=c_{t}+\gamma_{t} h_{t}+\varepsilon_{t} \\
\varepsilon_{t}=\xi_{t} \sqrt{h_{t}} \\
h_{t}=\omega+\alpha \varepsilon_{t-1}^{2}+\beta h_{t-1}
\end{gathered}
$$

where is the returns, $\mathbb{E}\left(\varepsilon_{t} \mid \mathcal{F}_{t-1}\right)=0,\left(\varepsilon_{t}^{2} \mid \mathcal{F}_{t-1}\right)=h_{t}, h_{t}$ is the conditional variance or risk and $\xi_{t} \sim$ i. i.d. $(0,1)$

In equation (11), the variance equation follows $\operatorname{GARCH}(1,1)$ process, which assumes $\varepsilon_{t}$ to have a normal distribution Engle (1982). However, the studied of Nelson (1991) reported a thick tail distribution of $\varepsilon_{t}$. Then, we 
decide to follow the studies of Li et al. (2005) and Linton and Perron (2003) to assume $\varepsilon_{t}$ to follow a Generalized Error Distribution (GED), which has a great benefit on cover the thick tail pattern in the distribution

In equation (9), the time-varying coefficients $\left(c_{t}, \gamma_{t}\right)$ cannot be estimated without knowing the series of. $h_{t}$ However, $h$, which depends on the GARCH process in equation (11), cannot be estimated without knowing the lagged of error term $(\varepsilon)$. Finally, we cannot get the lagged of error term $(\varepsilon)$ without knowing the time-varying coefficients in the mean equation.

In order to solve this problem, we apply the iterative estimation from Conrad and Manmen (2008). Our estimation procedure is described in the following steps.

Step 1: Perform the traditional GARCH-in-Mean to get the initial value of $\hat{h}_{t}^{(0)}$.

Step 2: Regress $r_{t}$ on $\hat{h}_{t}^{(0)}$ by using GAM approach to estimate the time varying coefficients, $\hat{c}_{t}^{(i)}$ and $\hat{\gamma}_{t}^{(i)}$ and, consequently, we can get $\hat{\varepsilon}_{t}^{(i)}$.

Step 3: Perform GARCH $(1,1)$ on $\hat{\varepsilon}_{t}^{(i)}$ to get the parameter $\hat{\omega}_{t}^{(i)}, \hat{\alpha}_{t}^{(i)}, \hat{\beta}_{t}^{(i)}$ and the updated value of $\hat{h}_{t}^{(i)}$.

Step 4: Repeat step 2 and 3 for a finite fixed number of iterations or until convergence.

In our study, the estimation algorithm is very stable and the convergence is quite fast in which less than 10 iterations. The following equation is a convergence criterion, which we apply it from Conrad and Manmen (2008).

$$
\Gamma(k)=\frac{\sum_{t=1}^{T}\left(\hat{y}_{t}^{k}-\hat{y}_{t}^{k-1}\right)^{2}}{\sum_{t=1}^{T}\left(\hat{y}_{t}^{k-1}\right)^{2}+\bar{c}}<\bar{c}
$$

where $k=1, \ldots, K$ are the number of iterations, $\hat{y}_{t}^{k}=\hat{c}_{t}^{k}+\hat{\gamma}_{t}^{k} \hat{h}_{t}^{k}$ and $\bar{c}$ is some small prespecified in which we follow Conrad and Manmen (2008) to choose $\bar{c}=0.001$.

\subsection{Data Description}

In this paper, we study the risk-return relationship in three major crude oil markets, which are West Texas Intermediate (WTI), Brent, and Dubai, and one Asian fuel oil market in Singapore Exchange (SGX). For the three crude oil markets, we have price unit in US dollar per barrel while, in the SGX market, we have a unit of price in US dollar per metric ton. For Brent and Dubai, we use the crude oil future on June 2020 contract, while for WTI we use the crude oil future on July 2020 contract.

All of the data sets are obtained from Bloomberg. We use the daily data from December 2, 2019, to May 29, 2020. The reason to use the data over this period is because it covers the important events of COVID-19 pandemic and 2020 oil price war. COVID-19 started to spread in Wuhan, China, on December 2019. WHO declared COVID-19 a Public Health Emergency of International Concern (PHEIC) on Jan 30, 2020. And the international organization declared COVID-19 a pandemic on March 11, 2020. In addition, the 2020 oil price war had started on March 8, 2020, following the break-up of negotiations between OPEC and Russia. The price of oil in WTI fell into negative price for the first time in recorded history on April 20, 2020.

The price on each market are converted to the return by using the formula: $r_{t}=\ln \left(\frac{p_{t}}{p_{t-1}}\right)$ before put into the model. The price and return of crude oil in all four markets are presented in Figure 1 with the vertical blue dot line indicating the opened market day after the oil price war had started on March 8, 2020.

\section{Results}

In this section, we provide the study results of the riskreturn relationship in the four major oil markets - Brent, Dubai, West Texas Intermediate (WTI), and Singapore Exchange (SGX).

Firstly, we perform the traditional GARCH-in-Mean model in order to compare with our time-varying coefficient GARCH-in-Mean model. The variance equation of the traditional model follows $\operatorname{GARCH}(1,1)$ process and assumes the error term to have follow a Generalized Error Distribution (GED), which allows to have a thick tail in distribution. The results on the traditional GARCH-in-Mean model are shown in Table 1. For the risk-return parameter, $\gamma$ we found a significant negative relationship between risk and return in Brent, Dubai, and SGX. However, for WTI, we found a significant positive relationship on risk and return. For the constant term, $c$, we found a strongly significant positive number in all four markets. However, the constant term, $c$, in all data sets is very small and close to zero. For the parameters in the variance equation $(\omega, \alpha, \beta)$, the parameter, $\omega$, is significant in all markets. The parameter $\alpha$ and $\beta$ are also strongly significant in all cases, with the large value of $\beta$ and the sum of $\alpha$ and $\beta$ close to one, which is standard (Christensen et al., 2012).

Secondly, we perform our time-varying coefficient GARCH-in-Mean model and the results are shown in Figure 2 and Table 2. Unlike the traditional GARCH-in-Mean model, the coefficients in the mean equation, $r_{t}=c_{t}+\gamma_{t} h_{t}+\varepsilon_{t}$, of our model can be varying over-time. Our estimated timevarying coefficients $\left(c_{t}, \gamma_{t}\right)$ and the $95 \%$ confident interval are shown in Figure 2. The left column of Figure 2 is the estimated time-varying coefficient $c$, while the right column is for $\gamma_{t}$. Each rows of Figure 2 represents oil markets. 
Napon HONGSAKULVASU, Asama LIAMMUKDA I
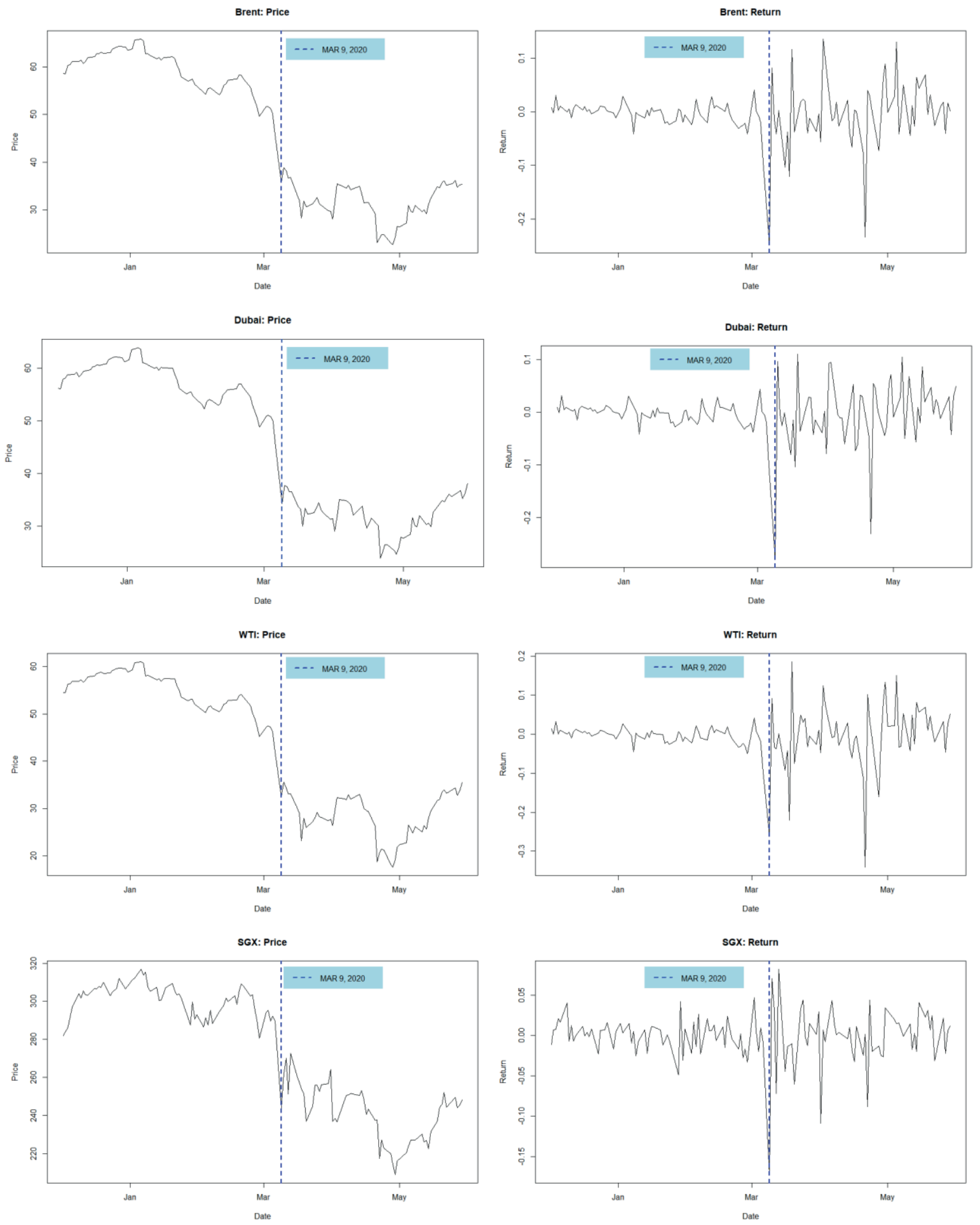

Figure 1: The price and return of oil in 4 major markets; Brent, Dubai, West Texas Intermediate (WTI) and Singapore Exchange (SGX) during December 2, 2019 to May 29, 2020. 
Table 1: Estimation results from the traditional GARCH-in-Mean model

\begin{tabular}{|c|c|c|c|c|}
\hline Coefficient & Brent & Dubai & WTI & SGX \\
\hline$c$ & $\begin{array}{c}0.002513^{* * *} \\
(0.000142)\end{array}$ & $\begin{array}{c}0.002395^{* * *} \\
(0.000085)\end{array}$ & $\begin{array}{c}0.000862^{* * *} \\
(0.000015)\end{array}$ & $\begin{array}{c}0.005979 * * * \\
(0.000275)\end{array}$ \\
\hline V & $\begin{array}{c}-0.172801^{* * *} \\
(0.040032)\end{array}$ & $\begin{array}{c}-0.315754^{* * *} \\
(0.052497)\end{array}$ & $\begin{array}{c}1.668859^{* * *} \\
(0.031063)\end{array}$ & $\begin{array}{c}-2.751739^{* * *} \\
(0.091287)\end{array}$ \\
\hline$\omega$ & $\begin{array}{c}0.000047^{* * *} \\
(0.000014)\end{array}$ & $\begin{array}{c}0.000047^{* * *} \\
(0.000018)\end{array}$ & $\begin{array}{c}0.000058^{* * *} \\
(0.000006)\end{array}$ & $\begin{array}{c}0.000047^{* * *} \\
(0.000003)\end{array}$ \\
\hline$\alpha$ & $\begin{array}{c}0.33327^{* * *} \\
(0.06269)\end{array}$ & $\begin{array}{c}0.314565^{* * *} \\
(0.045173)\end{array}$ & $\begin{array}{c}0.385811^{* * *} \\
(0.013494)\end{array}$ & $\begin{array}{c}0.120231^{* * *} \\
(0.005668)\end{array}$ \\
\hline$\beta$ & $\begin{array}{l}0.66573^{* * *} \\
(0.043623)\end{array}$ & $\begin{array}{c}0.684434^{* * *} \\
(0.044523)\end{array}$ & $\begin{array}{c}0.613189^{* * *} \\
(0.022602)\end{array}$ & $\begin{array}{c}0.846922^{* * *} \\
(0.020714)\end{array}$ \\
\hline
\end{tabular}

Note: $r_{t}=c+\gamma h_{t}+\varepsilon_{t}, h_{t}=\omega+\alpha \varepsilon_{t-1}^{2}+\beta h_{t-1}$. The robust standard errors are reported in parenthesis. Asterisks indicate statistical significance at the $10 \%\left({ }^{*}\right), 5 \%\left(^{* *}\right)$ or $1 \%\left(^{* * *}\right)$ level.

Table 2: Estimation results of conditional variance equation from Time-varying coefficient GARCH in Mean Model

\begin{tabular}{|l|c|c|c|c|}
\hline Coefficient & Brent & Dubai & WTI & SGX \\
\hline$\omega$ & $\begin{array}{l}0.00004 \\
(0.000029)\end{array}$ & $\begin{array}{c}0.000046 \\
(0.000036)\end{array}$ & $\begin{array}{c}0.000049 \\
(0.000029)\end{array}$ & $\begin{array}{c}0.000043 \\
(0.000041)\end{array}$ \\
\hline$\alpha$ & $0.2522^{* *}$ & $0.269232^{* * *}$ & $0.233053^{* * *}$ & $0.127782^{* *}$ \\
& $(0.108126)$ & $(0.104519)$ & $(0.06288)$ & $0.058493)$ \\
$\beta$ & $0.74681^{* * *}$ & $0.729768^{* * *}$ & $0.765947^{* * *}$ & $0.832703^{* * *}$ \\
& $(0.11208)$ & $(0.11341)$ & $(0.064901)$ & $(0.078133)$ \\
\hline
\end{tabular}

Note: Time-varying coefficient GARCH in Mean Model: $r_{t}=c_{t}+\gamma_{t} h_{t}+\varepsilon_{t}, h_{t}=\omega+\alpha \varepsilon_{t-1}^{2}+\beta h_{t-1}$. The robust standard errors are reported in parenthesis. Asterisks indicate statistical significance at the $10 \%\left({ }^{*}\right), 5 \%\left({ }^{* *}\right)$ or $1 \%\left({ }^{* * *}\right)$ level.

For the parameter $c_{t}$, we found a significant and negative value in all four markets, which are contrary to the results of the traditional GRACH-in-Mean model. The parameter $c_{t}$, in Brent is negative and significant from February 12 to April 20, 2020. For Dubai, $c_{t}$ is negative and significant from February 11 to April 24, 2020. For WTI, $c$ is negative and significant from February 26 to April 5, 2020. For SGX, $c_{t}$ is negative and significant from February 3, 2020.

For the risk-return parameter, $\gamma_{t}$, we found the results contrary to the traditional GARCH-in-Mean model on Brent, Dubai, and SPG market, while we found the same positive relationship on WTI. For the Brent crude oil market, our model found that there is a significant positive risk-return relationship between March 26 and April 21, 2020. For the Dubai crude oil market, our model found that there is a significant positive risk-return relationship between March 12 and April 14, 2020. For the WTI crude oil market, our model found a significant positive riskreturn relationship between March 12 and May 8, 2020. For the SGX oil market, our model found that there is a significant positive risk-return relationship from March 9, 2020.

The results from our time-varying coefficient GARCHin-Mean model are very interesting because they show that the risk and return are positive after the oil price war started in March 8, 2020. Before the oil price war, there is no risk-return relationship in all four markets. The positive risk-return relationship remains only a month and then, after the volatility or risk become lower in the end of April and the beginning of May, the risk-return relationship become insignificant. So, we can conclude that, in a normal situation, there is no risk-return relationship in crude oil market, but there is a positive risk-return relationship during the oil price war.

For the estimated parameters in the variance equation of our model, which follows $\operatorname{GARCH}(1,1)$, processes are shown in Table 2. The parameter $\omega$ is insignificant in all markets. The parameters $\alpha$ and $\beta$ are also strongly significant in all cases, with the large value of $\beta$ and the sum of $\alpha$ and $\beta$ close to one, which is standard (Christensen et al., 2012). 

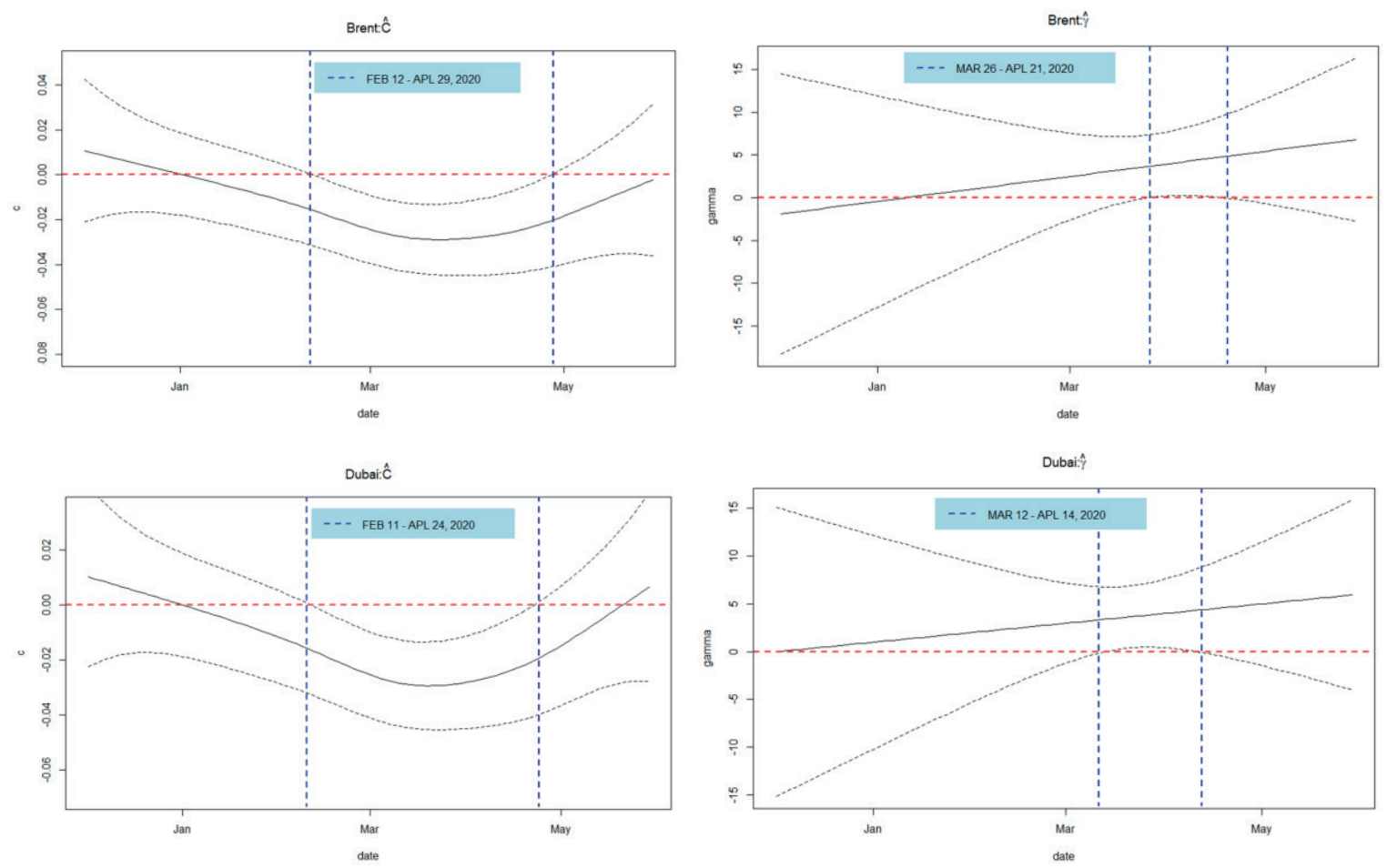

Dubaî̀
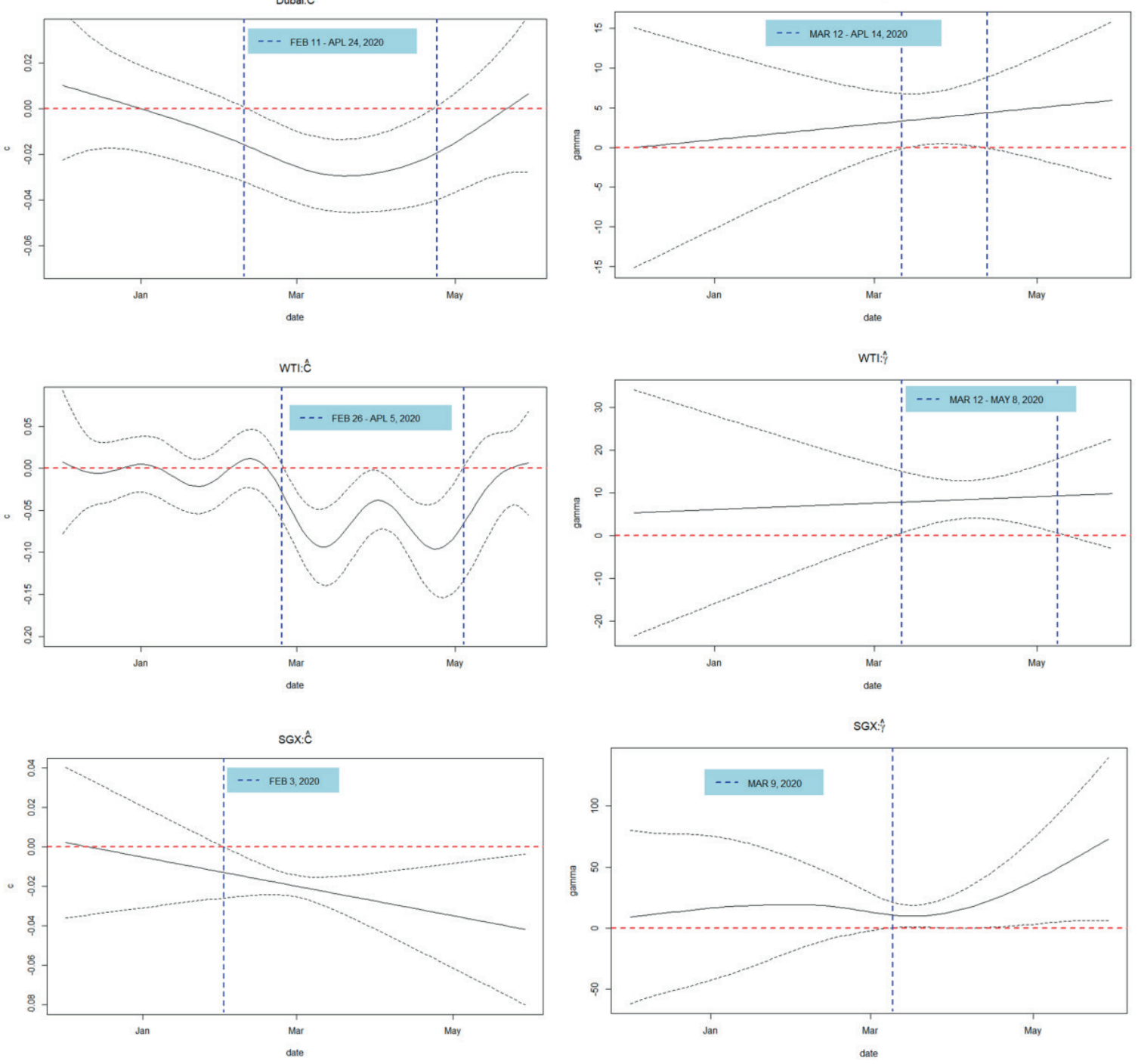

Note: The solid black line are the estimated time varying coefficients and the dot black lines are the area of $95 \%$ confident interval. Time-varying coefficient GARCH in Mean Model: $r_{t}=c_{t}+\gamma_{t} h_{t}+\varepsilon_{t}, h_{t}=\omega+\alpha \varepsilon_{t-1}^{2}+\beta h_{t-1}$.

Figure 2: The estimated Time-varying coefficients $\left(c_{t}, Y_{t}\right)$ of the Time-varying coefficient GARCH in Mean Model. 
Table 3: The goodness of fit comparison between the mean square error of the traditional GARCH-in-Mean model and the time-varying coefficient GARCH-in-Mean model.

\begin{tabular}{|l|l|c|c|c|c|}
\hline \multicolumn{2}{|l|}{ Model } & Brent & Dubai & WTI & SGX \\
\hline \multirow{2}{*}{$\begin{array}{l}\text { MSE of } \\
\text { Mean }\end{array}$} & GARCH-in-Mean & 0.002394 & 0.003973 & 0.002464 & 0.0009724 \\
\cline { 2 - 6 } & TV-GARCH-in-Mean & $0.002162^{*}$ & $0.003067^{*}$ & $0.002198^{*}$ & $0.0008586^{*}$ \\
\hline $\begin{array}{l}\text { MSE of } \\
\text { Variance }\end{array}$ & GARCH-in-Mean & 0.00006901 & 0.0002289 & 0.00008411 & 0.00001024 \\
\cline { 2 - 6 } & TV-GARCH-in-Mean & $0.00005213^{*}$ & $0.0000845^{*}$ & $0.00006408^{*}$ & $0.000006427^{*}$ \\
\hline
\end{tabular}

Note: “*” denote the lowest mean square error value of model. $\operatorname{MSE}($ mean $)=\frac{1}{T} \sum_{t=1}^{T}\left(r_{t}-\hat{c}_{t}-\hat{\gamma}_{t} \hat{h}_{t}\right)^{2}$,

$\operatorname{MSE}($ variance $)=\frac{1}{T} \sum_{t=1}^{T}\left[\left(r_{t}-\hat{c}_{t}-\hat{\gamma}_{t} \hat{h}_{t}\right)^{2}-\hat{h}_{t}\right]^{2}$

Lastly, in order to compare the performance of our time-varying coefficient GARCH-in-Mean model and the traditional GARCH-in-Mean model, we use the goodness of fit measures from Christensen et al. (2012) as is shown in the following equations.

$$
\begin{gathered}
\operatorname{MSE}(\text { mean })=\frac{1}{T} \sum_{t=1}^{T}\left(r_{t}-\hat{c}_{t}-\hat{\gamma}_{t} \hat{h}_{t}\right)^{2} \\
\operatorname{MSE}(\text { variance })=\frac{1}{T} \sum_{t=1}^{T}\left[\left(r_{t}-\hat{c}_{t}-\hat{\gamma}_{t} \hat{h}_{t}\right)^{2}-\hat{h}_{t}\right]^{2}
\end{gathered}
$$

The results on the goodness of fit are shown in Table 3. Our time-varying coefficient GARCH-in-Mean model provides the lower value of and than the traditional GARCHin-Mean model in all cases. So, it means that, to have the time-varying coefficients in the mean equation performs better than the traditional one.

\section{Conclusion}

In this paper, we propose the new time-varying coefficient GARCH-in-Mean model to study the risk and return relationship in four major oil markets during the COVID-19 pandemic and 2020 oil price war. Unlike the traditional GARCH-in-Mean model, in which the risk-return parameter is time invariant, our new model allows the coefficients in the mean equation to vary over time. After applying our new model to study the risk-return relationship in Brant, Dubai, WTI, and SGX, we found that, even though the COVID-19 started to spread around the world in December 2019, there was no risk-return relationship from December 2019 to the beginning of March, 2020. However, after the oil price war started in March 8, 2020, we found a positive and significant risk-return relationship in all four markets, but the relationship remains only a month and then disappeared with the reduction in market volatility. Finally, we show that our new model performs better than the traditional GARCHin-Mean model.

\section{References}

Abduikareem, A., \& Abdulhakeem, K. A. (2016). Analysing Oil Price-Macroeconomic Volatility in Nigeria. CBN Journal of Applied Statistics, 7(1)(a).

Bollerslev, T. (1986). Generalized autoregressive conditional heteroskedasticity, Journal of Econometrics, 31(3), 307-327.

Bringmann, L. F., Hamaker, E. L., Vigo, D. E., Aubert, A., Borsboom, D., \& Tuerlinckx, F. (2017). Changing dynamics: Time-varying autoregressive models using generalized additive modeling. Psychological Methods, 22(3), 409-425.

Christensen, B. J., Dahl, C. M., \& Iglesias, E. M. (2012). Semiparametric inference in a GARCH-in-mean model. Journal of Econometrics, 167(2), 458-472.

Cifarelli, G., \& Paladino, G (2010). Oil price dynamics and speculation. Energy Economics, 32, 363-372.

Conrad, C., \& Mammen, E. (2008). Nonparametric regression on latent covariates with an application to semiparametric GARCH-in-mean models. Discussion Paper No. 473. Department of Economics, University of Heidelberg.

Cotter, J., \& Hanly, J. (2010). Time-varying risk aversion: An Application to energy hedging. Energy Economics, 32, 432-441.

Deebom, Z. D., \& Essi, I. D. (2017). Modeling Price Volatility of Nigerian Crude Oil Markets Using GARCH Model: 1987-2017. International Journal of Applied Science and Mathematical Theory, 3(4), 23-49. https://iiardpub.org/get/IJASMT/VOL.\%20 3\%20NO.\%204\%202017/MODELING\%20PRICE.pdf

Engle, R. F. (1982). Autoregressive conditional heteroscedasticity with estimates of the variance of United Kingdom inflation. Econometrica, 50(4), 987-1007. https://www.jstor.org/ stable/1912773 
Engle, R. F., Lilien, D. M., \& R. P. Robins (1987). Estimating time varying risk premia in the term structure: The ARCH-M model. Econometrica, 55(2), 391-407. https://www.jstor.org/ stable/1913242

Gong X., Wen, F., Xia, X. H., Huang, J., \& Pan, B. (2017). Investigating the risk-return trade-off for crude oil futures using high-frequency data. Applied Energy, 196, 152-161.

Haslbeck, J., Bringmann, L. \& Waldorp, L. (2017). How to estimate time-varying Vector Autoregressive Models? A comparison of two methods. Retrieved from https://www.researchgate.net/ publication/321095790_How_to_estimate_time-varying_Vector_ Autoregressive_Models_A_comparison_of_two_methods

Hastie, T. J., \& Tibshirani, R. J. (1990). Generalized additive models. Boca Raton, FL: Chapman and Hall/CRC.

Hongsakulvasu, N., \& Liammukda, A. (2020). Asian Stock Markets Analysis: The New Evidence from Time-Varying Coefficient Autoregressive Model. Journal of Asian Finance, Economics and Business, 7(9), 95-104. https://doi.org/10.13106/ jafeb.2020.vol7.no9.095

Kristoufek, L. (2014). Leverage effect in energy futures. Energy Economics, 45(C), 1-9.

Li, Q., Yang, J., Hsiao, C., \& Chang, Y. J. (2005). The relationship between stock returns and volatility in international stock markets. Journal of Empirical Finance, 12(5), 650-665.

Li, Z., Sun, J., \& Wang, S. (2013). An information diffusion-based model of oil futures price. Energy Economics, 36, 518-525.

Linton, O., \& Perron, B. (2003). The shape of the risk premium: evidence from a semiparametric generalized autoregressive conditional heteroscedasticity model. Journal of Business \& Economic Statistics, 21(3), 354-367.
Merton, R. C. (1973). An intertemporal capital asset pricing model. Econometrica, 41(5), 867-887. https://www.jstor.org/ stable/1913811

Nelson, D. B. (1991). Conditional heteroskedasticity in asset returns: A new approach. Econometrica, 59(2), 347-370. https://www.jstor.org/stable/2938260

Nguyen, C. T., \& Nguyen, M. H. (2019). Modeling Stock Price Volatility: Empirical Evidence from the Ho Chi Minh City Stock Exchange in Vietnam. Journal of Asian Finance, Economics and Business, 6(3), 19-26. https://doi.org/10.13106/ jafeb.2019.vol6.no3.19

Sahadudheen, I. (2015). An Exponential GARCH Approach to the Effect of Impulsiveness of Euro on Indian Stock Market. Journal of Asian Finance, Economics and Business, 2(3), 17-22. https://doi.org/10.13106/jafeb.2015.vol2.no3.17

Trolle, A. B., \& Schwartz, E. S. (2008). Variance Risk Premia in Energy Commodities. Journal of Derivatives, 17, 15-32.

U.S. Energy Information Administration. (2020). Short-Term Energy Outlook.Retrievedfromhttps://www.eia.gov/outlooks/steo/report/ global_oil.php?fbclid=IwAR28xHG1vuVEGAZq6uHe4ZHh_ aOr83gd1L108Hn1Af-ntvt8X9PnHQV71js.

Wahba, G. (1980). Spline bases, regularization, and generalized cross validation for solving approximation problems with large quantities of noisy data. In: E. Cheney (Ed.), Approximation Theory III. London, UK: Academic Press.

Wood, S. N. (2003). Thin plate regression splines. Journal of the Royal Statistical Society, Series B, 65, 95-114.

Wood, S. N. (2006). Generalized additive models: An introduction with R. Boca Raton, FL: Chapman and Hall/CRC. 